\title{
Extended Radial Point Interpolation Method for crack analysis in orthotropic media
}

- Nguyen Thanh Nha

- Bui Quoc Tinh

- Truong Tich Thien

Ho Chi Minh city University of Technology, VNU-HCM

(Manuscript Received on August 01st, 2015, Manuscript Revised August 27th, 2015)

\section{ABSTRACT:}

Orthotropic materials are particular type of anisotropic materials; In contrast with isotropic materials, their properties depend on the direction in which they are measured. Orthotropic composite materials and their structures have been extensively used in a wide range of engineering applications. Studies on their physical behaviors under in-work loading conditions are essential. In this present, we apply an extended meshfree radial point interpolation method (XRPIM) for analyzing crack behaviour in $2 D$ orthotropic materials models. The thin plate spline (TPS) radial basis function (RBF) is used for constructing the RPIM shape functions. Typical advantages of using RBF are the satisfaction of the Kronecker's delta property and the high-order continuity. To calculate the stress intensity factors (SIFs), Interaction integral method with orthotropic auxiliary fields are used. Numerical examples are performed to show the accuracy of the approach; the results are compared with available refered results. Our numerical experiments have shown a very good performance of the present method.

Key words: orthotropic, crack, stress intensity factors, meshless, RPIM

\section{INTRODUCTION}

Orthotropic composite materials and their structures are used widely in various fields in engineering. One of the most preeminent property of composite is the high strength to weight ratio in comparison with conventional engineering materials. In many cases, orthotropic composites are fabricated in thin plate forms which are so susceptible to fault. A typical fault in composite structure is cracking due to inperfection in fabrication process or hard working conditions such as overload, fatigue, corrosion and so on. For the reason that, crack behavior of orthotropic materials has become an interesting study subject.
In the analytical field, there are some important results early given by $\mathrm{Sih}$ et al [1], Bowie et al [2], Tupholme et al [3], Barnet et al [4] and Kuo and Bogy [5]. They forcused on finding out the singular fields such as stress and displacement at near crack tip in anisotropic models. More recent contributions can be listed in Nobile et al [6, 7] and Carloni et al [8, 9].

There are several numerical studies that have performed to obtain the fracture behavior of orthotropic materials such as the extended finite element method (XFEM) [10, 11, 12]. In XFEM, the finite element approximation is enriched with 
Heaviside function for crack face and appropriate functions extracted from the analytical solutions for a crack tip near field. Moreover, the element free Galerkin method (EFG) [13] has been applied for fracture analysis of composite by Ghorashi et al [14]. In this aproach, the support domain is modified to involve the discontinuity at the crack face and the singularity at the crack tip. Unlike the FEM, a set of scattered nodes is used to model the domain in the meshfree methods. Since no finite element mesh is required in the approximation, meshfree methods are very suitable for modeling crack growth problems [15, $16,17,18]$.

In this work, we present an extended meshfree Galerkin method based on the radial point interpolation method (XRPIM) associated with the vector level set method for modeling the crack problem in orthotropic materials under static and dynamic loading conditions. To calculate the SIFs, the dynamic form of interaction integral formulation for homogeneous orthotropic materials is taken. Several numerical examples including static, dynamic SIFs calculation are performed and investigated to highlight the accuracy of the proposed method.

\section{FRACTURE MECHANICS FOR RTHOTROPIC MATERIALS}

The linear elastic stress-strain relations can be written as

$\boldsymbol{\varepsilon}=\mathbf{C \sigma}$

where $\boldsymbol{\sigma}, \boldsymbol{\varepsilon}$ are linear stress and strain vector respectivily and $\mathbf{C}$ is the fourth-order compliance tensor, in 2D, $\mathbf{C}$ can be defined as:

$$
\mathbf{C}^{3 D}=\left[\begin{array}{cccccc}
\frac{1}{E_{1}} & \frac{-v_{21}}{E_{2}} & \frac{-v_{31}}{E_{3}} & 0 & 0 & 0 \\
\frac{-v_{12}}{E_{1}} & \frac{1}{E_{2}} & \frac{-v_{32}}{E_{3}} & 0 & 0 & 0 \\
\frac{-v_{13}}{E_{1}} & \frac{-v_{23}}{E_{2}} & \frac{1}{E_{3}} & 0 & 0 & 0 \\
0 & 0 & 0 & \frac{1}{G_{23}} & 0 & 0 \\
0 & 0 & 0 & 0 & \frac{1}{G_{13}} & 0 \\
0 & 0 & 0 & 0 & 0 & \frac{1}{G_{12}}
\end{array}\right]
$$

where $E, G$ and $v$ are Young's modulus, shear modulus and Poisson's ratio, respectively.

For a plane stress state, with $i, j=1,2,6, \mathbf{C}$ can be simplified into:

$C_{i j}^{2 D}=C_{i j}^{3 D}$

For a plane strain state, $\mathbf{C}$ can be written as:

$C_{i j}^{2 D}=C_{i j}^{3 D}-C_{i 3}^{3 D} C_{j 3}^{3 D} / C_{33}^{3 D}$

Consider an anisotropic cracked body subjected to arbitrary forces with general boundary conditions as shown in Fig. 1. Global Cartesian coordinate $\left(X_{1}, X_{2}\right)$, local Cartesian coordinate $\left(x_{1}, x_{2}\right)$ and local polar coordinate $(r, \varphi)$ defined on the crack tip are also displayed in Fig. 1. Using equilibrium and compatibility conditions [19], a four-order partial differential equation with the following characteristic equation can be obtained 


$$
\begin{aligned}
C_{11}^{2 D} s^{4}-2 C_{16}^{2 D} & +\left(2 C_{12}^{2 D}+C_{66}^{2 D}\right) s^{2} \\
& -2 C_{26}^{2 D} s+C_{22}^{2 D}=0
\end{aligned}
$$

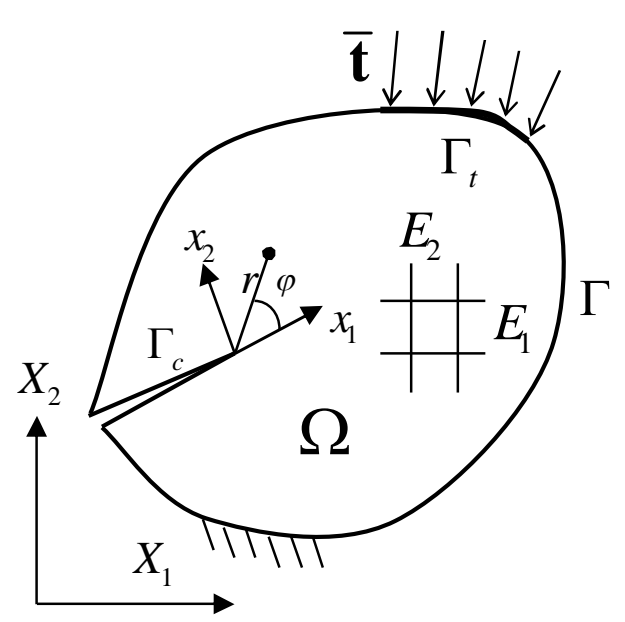

Figure 1. Orthotropic crack model

It was proved by Lekhnitskii [19] that the roots of Eq. (5) are always complex or purely imaginary $\left(s_{k}=s_{k x}+i s_{k y}, k=1,2\right)$ and occur in conjugate pairs as $s_{1}, \bar{s}_{1}$ and $s_{2}, \bar{s}_{2}$.

According to Sih et al [1], displacement and stress fields in the vicinity of the crack tip are

Mode I:

$u_{1}=K_{I} \sqrt{2 r / \pi} \operatorname{Re}\left[\left(s_{1}-s_{2}\right)^{-1}\right.$

$\left.\left(s_{1} p_{2} \sqrt{\cos \varphi+s_{2} \sin \varphi}-s_{2} p_{1} \sqrt{\cos \varphi+s_{1} \sin \varphi}\right)\right]$

$u_{2}=K_{I} \sqrt{2 r / \pi} \operatorname{Re}\left[\left(s_{1}-s_{2}\right)^{-1}\right.$

$\left.\left(s_{1} q_{2} \sqrt{\cos \varphi+s_{2} \sin \varphi}-s_{2} q_{1} \sqrt{\cos \varphi+s_{1} \sin \varphi}\right)\right]$

$\sigma_{11}=\frac{K_{I}}{\sqrt{2 \pi r}} \operatorname{Re}\left[\frac{s_{1} s_{2}}{s_{1}-s_{2}}\right.$

$\left.\left(s_{2}\left(\cos \varphi+s_{2} \sin \varphi\right)^{-0.5}-s_{1}\left(\cos \varphi+s_{1} \sin \varphi\right)^{-0.5}\right)\right]$

$\sigma_{22}=\frac{K_{I}}{\sqrt{2 \pi r}} \operatorname{Re}\left[\frac{1}{s_{1}-s_{2}}\right.$

$\left.\left(s_{1}\left(\cos \varphi+s_{2} \sin \varphi\right)^{-0.5}-s_{2}\left(\cos \varphi+s_{1} \sin \varphi\right)^{-0.5}\right)\right]$

$\sigma_{12}=\frac{K_{I}}{\sqrt{2 \pi r}} \operatorname{Re}\left[\frac{s_{1} s_{2}}{s_{1}-s_{2}}\right.$

$\left.\left(\left(\cos \varphi+s_{1} \sin \varphi\right)^{-0.5}-\left(\cos \varphi+s_{2} \sin \varphi\right)^{-0.5}\right)\right]$

(6)
Mode II:

$$
\begin{aligned}
& u_{1}=K_{I I} \sqrt{2 r / \pi} \operatorname{Re}\left[\left(s_{1}-s_{2}\right)^{-1}\right. \\
& \left.\left(p_{2} \sqrt{\cos \varphi+s_{2} \sin \varphi}-p_{1} \sqrt{\cos \varphi+s_{1} \sin \varphi}\right)\right] \\
& u_{2}=K_{I I} \sqrt{2 r / \pi} \operatorname{Re}\left[\left(s_{1}-s_{2}\right)^{-1}\right. \\
& \left.\left(q_{2} \sqrt{\cos \varphi+s_{2} \sin \varphi}-q_{1} \sqrt{\cos \varphi+s_{1} \sin \varphi}\right)\right] \\
& \sigma_{11}=\frac{K_{I}}{\sqrt{2 \pi r}} \operatorname{Re}\left[\left(s_{1}-s_{2}\right)^{-1}\right. \\
& \left.\left(s_{2}^{2}\left(\cos \varphi+s_{2} \sin \varphi\right)^{-0.5}-s_{1}^{2}\left(\cos \varphi+s_{1} \sin \varphi\right)^{-0.5}\right)\right] \\
& \sigma_{22}=\frac{K_{I I}}{\sqrt{2 \pi r}} \operatorname{Re}\left[\left(s_{1}-s_{2}\right)^{-1}\right. \\
& \left.\left(\left(\cos \varphi+s_{2} \sin \varphi\right)^{-0.5}-\left(\cos \varphi+s_{1} \sin \varphi\right)^{-0.5}\right)\right] \\
& \sigma_{12}=\frac{K_{I}}{\sqrt{2 \pi r}} \operatorname{Re}\left[\left(s_{1}-s_{2}\right)^{-1}\right. \\
& \left.\left(s_{1}\left(\cos \varphi+s_{1} \sin \varphi\right)^{-0.5}-s_{2}\left(\cos \varphi+s_{2} \sin \varphi\right)^{-0.5}\right)\right]
\end{aligned}
$$

where $p_{k}, q_{k}$ are defined by

$$
\begin{gathered}
p_{k}=C_{11} s_{k}^{2}+C_{12}-C_{16} s_{k} \\
p_{k}=C_{11} s_{k}^{2}+C_{12}-C_{16} s_{k}
\end{gathered}
$$

\section{XRPIM FORMULATION FOR CRACK PROBLEM}

\subsection{Meshless XRPIM discretization and vector level set method}

Base on the extrinsic enrichment technique, the displacement approximation is rewritten in terms of the signed distance function $f$ and the distance from the crack tip as follow:

$$
\begin{gathered}
u^{h}(\mathbf{x}, t)=\sum_{I \in W(\mathbf{x})} \phi_{I}(\mathbf{x}) u_{I}+\sum_{I \in W_{b}(\mathbf{x})} \phi_{I}(\mathbf{x}) \alpha_{I} H(f(\mathbf{x})) \\
+\sum_{I \in W_{S}(\mathbf{x})} \phi_{I}(\mathbf{x}) \sum_{j=1}^{4} B_{j}(\mathbf{x}) \beta_{l j}
\end{gathered}
$$

where $\phi_{I}$ is the RPIM shape functions [20] and $f(\mathbf{x})$ is the signed distance from the crack line. The jump enrichment functions $H(f(\mathbf{x}))$ and the vector of branch enrichment functions $B_{j}(\mathbf{x}) \quad(j=1,2,3,4)$ are defined respectively by 


$$
\begin{aligned}
& H(f(\mathbf{x}))= \begin{cases}+1 & \text { if } f(\mathbf{x})>0 \\
-1 & \text { if } f(\mathbf{x})<0\end{cases} \\
& B(\mathbf{x})=\left(\sqrt{r} \sin \frac{\varphi}{2}, \sqrt{r} \cos \frac{\varphi}{2},\right. \\
& \left.\sqrt{r} \sin \frac{\varphi}{2} \sin \varphi, \sqrt{r} \cos \frac{\varphi}{2} \sin \varphi\right)
\end{aligned}
$$

where $r$ is the distance from $\mathrm{x}$ to the crack tip $\mathbf{x}_{T I P}$ and $\varphi$ is the angle between the tangent to the crack line and the segment $\mathbf{x}-\mathbf{x}_{T I P}$ as shown in Fig. 2. $W_{b}$ denotes the set of nodes whose support contains the point $\mathrm{x}$ and is bisected by the crack line and $W_{s}$ is the set of nodes whose support contains the point $\mathrm{x}$ and is slit by the crack line and contains the crack tip. $\alpha_{I}, \beta_{I j}$ are additional variables in the variational formulation.

\subsection{Discrete equations}

Substituting the approximation (9) into the well-known weak form for solid problem, using the meshless procedure, a linear system of equation can be written as

$$
\mathbf{K u}=\mathbf{F}
$$

with $\mathbf{K}$ being the stiffness matrix, respectively, and $\mathbf{F}$ being the vector of force, they can be defined by

$$
\begin{aligned}
& \mathbf{K}_{I J}=\int_{\Omega} \mathbf{B}_{I}^{T} \mathbf{D} \mathbf{B}_{J} d \Omega \\
& \mathbf{F}_{I}=\int_{\Omega} \boldsymbol{\Phi}_{I}^{T} \mathbf{b}_{I} d \Omega+\int_{\Gamma_{t}} \boldsymbol{\Phi}_{I}^{T} \overline{\mathbf{t}}_{I} d \Gamma
\end{aligned}
$$

where $\boldsymbol{\Phi}$ is the vector of enriched RPIM shape functions; the displacement gradient matrix B must be calculated appropriately dependent upon enriched or non-enriched nodes.

\section{J-INTEGRAL FOR DYNAMIC SIFS IMPLEMENTATION}

The dynamic stress intensity factors are important parameters, and they are used to calculate the positive maximum hoop stress to evaluate dynamic crack propagation properties. The dynamic form of J-integral for orthotropic material can be adopted [21]

$$
J^{d y n}=\int_{V_{\mathrm{r}}}\left(\sigma_{i j} u_{i, 1}-(W-K) \delta_{1 j}\right) q_{, j} d A
$$

where $W=1 / 2 \sigma_{i j} \varepsilon_{i j}$ is strain energy density; $q$ is a weight function, changing from $q=1$ near a crack-tip and $q=0$ at the exterior boundary of the $J$ domain.

In this paper, the interaction integral technique is applied to extract SIFs. After some mathematical transformations, the path independent integration can be written as

$$
M=\int_{A}\left(\sigma_{i j} u_{i, 1}^{a u x}+\sigma_{i j}^{a u x} u_{i, 1}-\sigma_{i j}^{a u x} \varepsilon_{i j} \delta_{1 j}\right) q_{, j} d A
$$

The stress intensity factors can then be evaluated by solving a system of linear algebraic equations:

$$
\begin{aligned}
& M^{(1)}=2 d_{11} K_{I}+d_{12} K_{I I} \\
& M^{(1)}=d_{12} K_{I}+2 d_{22} K_{I I}
\end{aligned}
$$

where

$$
d_{11}=-\frac{C_{11}}{2} \operatorname{Im}\left(\frac{s_{1}+s_{2}}{s_{1} s_{2}}\right),
$$

$$
\begin{gathered}
d_{22}=\frac{C_{11}}{2} \operatorname{Im}\left(s_{1}+s_{2}\right) \\
d_{12}=-\frac{C_{22}}{2} \operatorname{Im}\left(\frac{1}{s_{1} s_{2}}\right)+\frac{C_{11}}{2} \operatorname{Im}\left(s_{1} s_{2}\right),
\end{gathered}
$$

\section{NUMERICAL EXAMPLES}

\subsection{Rectangular edge crack plate with various of the axes of orthotropy}

A rectangular orthotrpic plate with an edge horizontal crack is considered in this example. Several orientation of orthotropic axes are investigated in SIFs calculation. The dimensions and load condition are shown in Fig. 2. The orthotropic material properties are given as 
$E_{1}=114.8 G P a, \quad E_{2}=117 G P a, \quad v_{12}=0.21, \quad$ and $G_{12}=9.66 G P a$. The plane stress state is assumed in this problem.

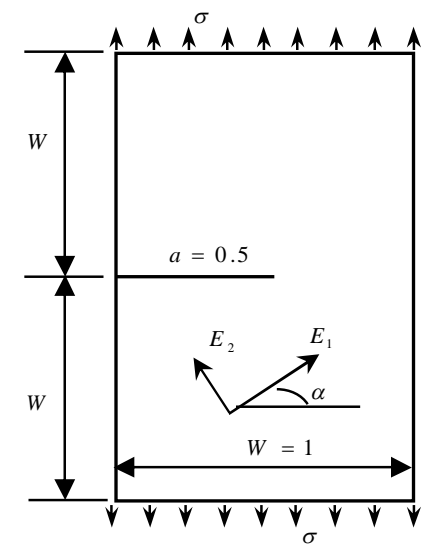

Figure 2. Orthotropic edge crack plate

A model with $20 \times 40$ regular distributed nodes is used. A coefficient defined for the support domain $\alpha=2.2$ is taken. The are five values of orientations of the axes of orthotropy $\left(\alpha=0^{\circ}, 30^{\circ}, 45^{\circ}, 60^{\circ}\right.$ and $\left.90^{\circ}\right)$ are taken in account in the problem. The results are compared with XFEM solution given by Asadpoure et al [10] with 1925 nodes and FEM solution given by Aliabadi [22]. The plot in Fig. 3 show the comparison and it can be see that the single mode obtained at $\alpha=0^{\circ}$ and $\alpha=90^{\circ}$. In mode I, the normalized SIF increases from $\alpha=0^{\circ}$ to $\alpha=45^{\circ}$ and then decreases to $\alpha=90^{\circ}$. It is different from mode II, the maximum SIF obtained at $\alpha=30^{\circ}$.

Charts in Fig. 4 and Fig. 5 show the effect of the coefficient of support domain size. It can be seen that the values of $\alpha_{d}$ from 2.0 to 2.2 give acceptable results.

\subsection{Cantilever orthotropic plate under shear stress}

In this example, a cantilever rectangular plate made of orthotropic material with an edge crack at left side is considered. The plate is subjected to a shear loading at the top edge. Dimension, load and boundary condition are display in Fig. 6. The orthotropic material properties are the same with the previous example.

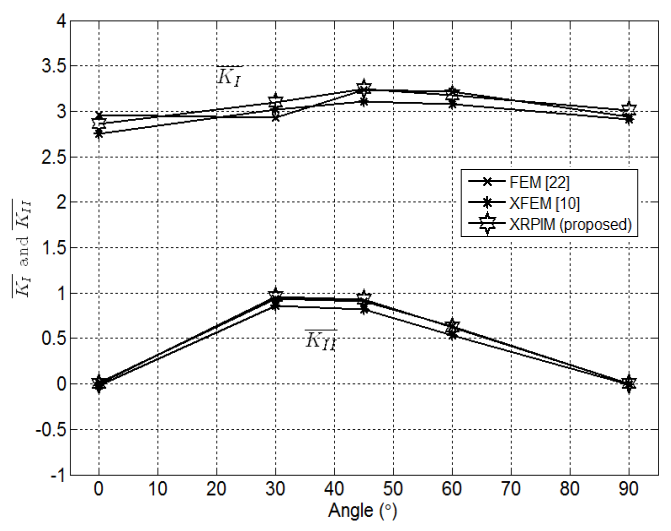

Figure 3. Normalized SIFs results with several orientations of the axes of orthotropy

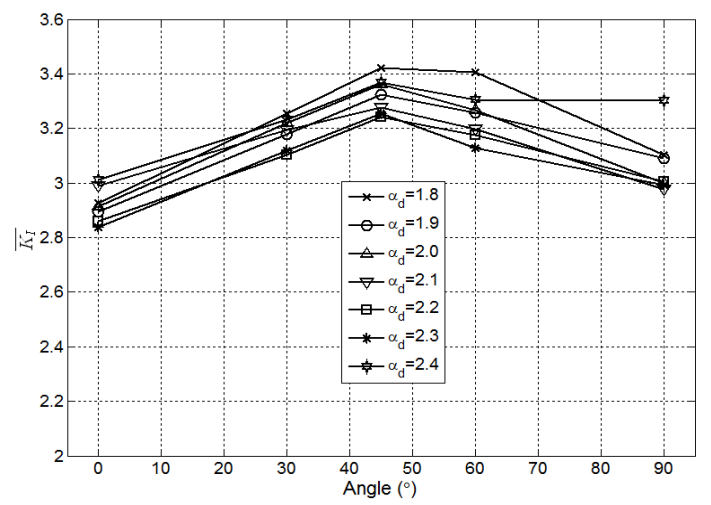

Figure 4. Normalized mode I SIFs results with coefficients of support domain size $\alpha_{d}$

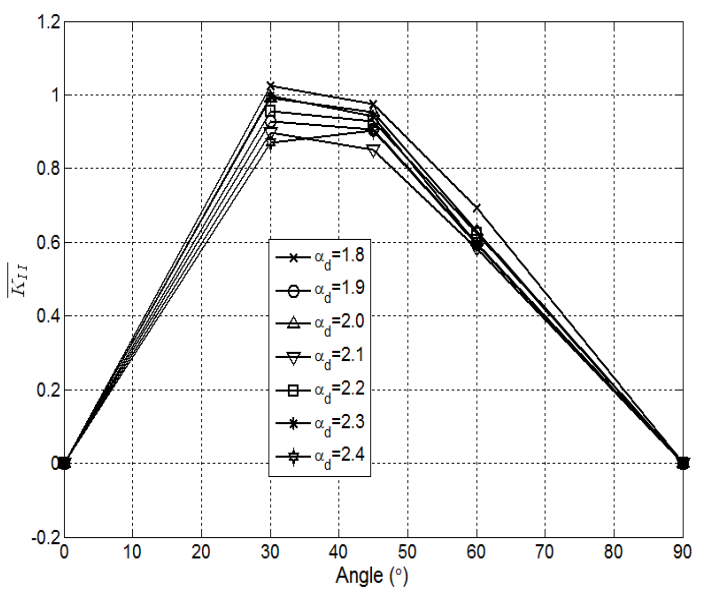

Figure 5. Normalized mode II SIFs results with coefficients of support domain size $\alpha_{d}$ 
The orthotropic material properties are the same with the previous example.

There are $20 \times 40$ regular distributed nodes are used in this plane stress analysis. Several values of orthotropic material axes are considered (from -90 to 90 degree).

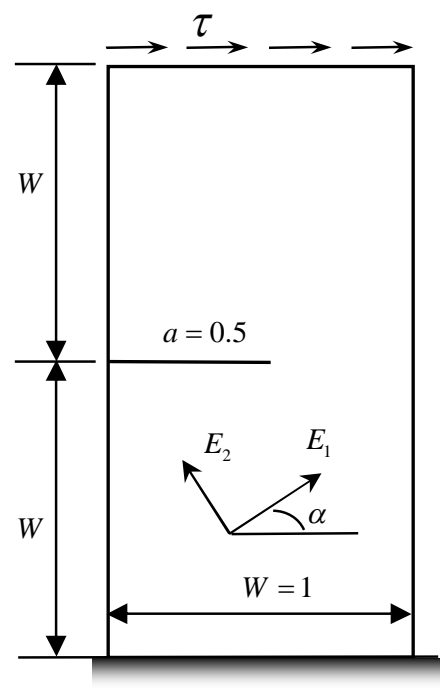

Figure 6. Orthotropic edge crack plate under shear loading

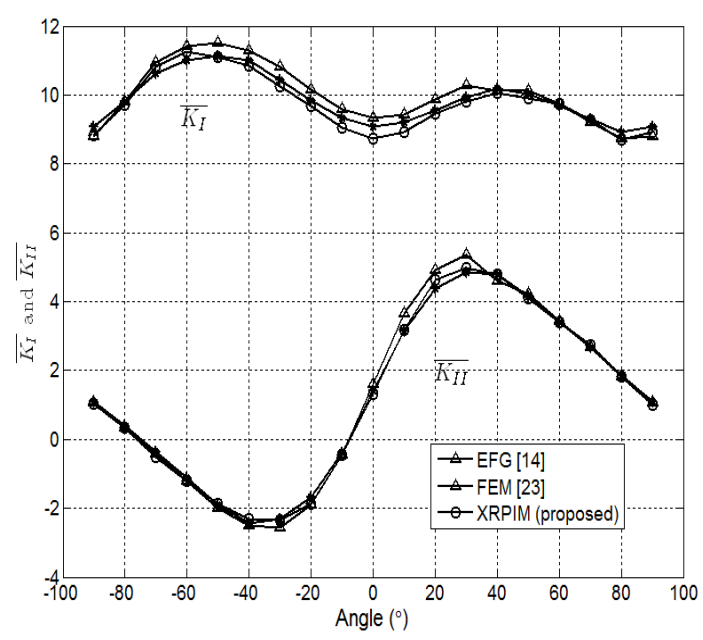

Figure 7. Normalized SIFs results with several orientations of the axes of orthotropy

The plots in Fig. 7 show the mixed-mode values of stress intensity factor with respect to various orthotropic angle from $-90^{\circ}$ to $90^{\circ}$. The obtained results from the proposed XRIM approach are compared with EFG solutions given by Ghorashi et al [14] and FEM solutions from Chu and Hong [23]. A very close agreement is acquired.

\subsection{Orthotropic plate with central slant crack}

The last example studies a rectangular orthotropic plate with a slanted crack at center. As shown in Fig. 8 , the dimensions parameters are $H=2 W=2, \quad 2 a=2 \sqrt{2}, \quad \alpha=45^{\circ} . \quad$ The orthotropic material properties are given as $E_{1}=3.5 G P a, \quad E_{2}=12 G P a, \quad v_{21}=0.7, \quad$ and $G_{12}=3.0 G P a$. The problem is performed with $30 \times 60$ nodes and mixed-mode SIFs are compared with available analytical and numerical solutions as shown in Table 1

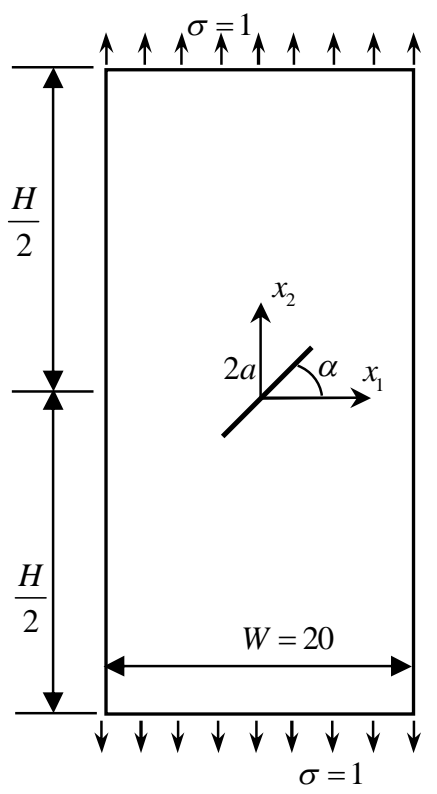

Figure 8. Orthotropic plate with central slanted crack

Table 1. Mix-mode normalized SIFs for plate with central slanted crack $\bar{K}=K / \sigma \sqrt{\pi a}$

\begin{tabular}{|l|c|c|}
\hline Method & $\bar{K}_{I}$ & $\bar{K}_{I I}$ \\
\hline XRPIM & 0.523 & 0.475 \\
\hline Sih et al [1] & 0.500 & 0.500 \\
\hline
\end{tabular}




\begin{tabular}{|l|c|c|}
\hline Atluri et al [24] & 0.484 & 0.512 \\
\hline Kim and Paulino [25] & 0.506 & 0.495 \\
\hline Ghorashi et al [14] & 0.512 & 0.530 \\
\hline Asadpoure et al [12] & 0.514 & 0.519 \\
\hline
\end{tabular}

\section{CONSLUSION}

A meshless extended radial point interpolation method (XRPIM) has been proposed for cracks analysis in orthotropic median under different loadings and several material orientations. This method is convenient in treating the Dirichlet boundary conditions because of the RPIM shape functions satisfying the Kronecker's delta property. Several numerical examples are considered with different material models and loading conditions. The obtained solutions show a good agreement of between the proposed method and the references. The presented approach has shown several advantages and it is promising to be extended to more complicated problems such as dynamic crack analysis and crack propagation problems for orthotropic materials.

\section{Phương pháp không lưới RPIM mở rộng cho bài toán nứt trong vật liệu trực hướng}

- Nguyễn Thanh Nhã

- Bùi Quốc Tính

- Trương Tích Thiện

Trường Đại học Bách khoa, ĐHQG-HCM

\section{TÓM TÁT:}

Vật liệu trực hướng là một dạng đặc biệt trong nhóm vật liệu bất đẳng hướng. Không như vật liệu đẳng hướng, các thuộc tính cơ học của chúng phụ thuộc vào các phương tọa độ nhất định. Vật liệu composite trực hướng và các kết cấu của chúng ngày nay được sử dụng rộng rãi trong các ứng dụng kỹ thuật. Việc nghiên cứu các ứng xử của chúng dưới các điều kiện tải trọng làm việc là rất cần thiết. Trong nghiên cứu này, tác giả áp dụng phương pháp không lưới mở rộng dựa trên phép nội suy điểm hướng kính (XRPIM) cho bài toán phân tích nứt trong vật liệu composite trực hướng. Dạng hàm cơ sở hướng kính (RBF) với hàm spline (TPS) được dùng để cấu tạo hàm dạng RPIM. Các ưu điểm của hàm 
cơ sở hướng kính là thỏa mãn thuộc tính Kronecker's delta và liên tục bậc cao. Để tính toán hệ số cường độ ứng suất (SIF), phương pháp tích phân tương tác được sử dụng kết hợp với miền phụ trợ trực hướng lân cận đỉnh vết nứt. Các ví dụ số được thực hiện nhằm kiểm chứng sự chính xác của phương pháp. Các lời giải từ XRPIM được so sánh với các lời giải tham khảo từ các phương pháp khác. Kết quả so sánh cho thấy phương pháp được chọn phù hợp đối với bài toán đã đề cập.

Từ khóa: vật liệu trực hướng, hệ số cường độ ứng suất, phương pháp không lưới RPIM

\section{REFERENCES}

[1]. Sih GC, Paris PC, Irwin GR. On cracks in rectilinearly anisotropic bodies. Int $\mathrm{J}$ Fract Mech 1965;1:189-203.

[2]. Bowie OL, Freese CE. Central crack in plane orthotropic rectangular sheet. Int $\mathbf{J}$ Fract Mech 1972;8:49-58.

[3]. Tupholme G. E. A study of cracks in orthotropic crystals using dislocations layers, J. Eng. Math. 1974; 8, 57-69.

[4]. Barnett DM, Asaro RJ. The fracture mechanics of slit-like cracks in anisotropic elastic media. J Mech Phys Solids 1972; 20:353-66.

[5]. Kuo MC, Bogy DB. Plane solutions for the displacement and traction-displacement problem for anisotropic elastic wedges. J Appl. Mech 1974; 41:197-203

[6]. Nobile L, Carloni C. Fracture analysis for orthotropic cracked platest. Comp Struct 2005; 68(3), 285-93.

[7]. Nobile L, Piva A, Viola E. On the inclined crack problem in an orthotropic medium under biaxial loading. Eng Fract Mech 2004; 71, 529-46.

[8]. Carloni C, Nobile L. Crack initiation behaviour of orthotropic solids as predicted by the strain energy density theory. Theoret Appl Fract Mech 2002; 38, 109-19.

[9]. Carloni C, Piva A, Viola E. An alternative complex variable formulation for an inclined crack in an orthotropic medium. Eng Fract Mech 2003; 70, 2033-58

[10].A. Asadpoure, S. Mohammadi, A. Vafait. Crack analysis in orthotropic media using the extended finite element method. ThinWalled Structures 2006; 44, 1031-1038.

[11].A. Asadpourea, S. Mohammadi, A. Vafait. Modeling crack in orthotropic media using a coupled finite element and partition of unity methods. Finite Elements in Analysis and Design 2006; 42; 1165 - 1175.

[12].A. Asadpoure, S. Mohammadi. Developing new enrichment functions for crack simulation in orthotropic media by the extended finite element method. Int. J. Numer. Meth. Engng 2007; 69, 2150-2172.

[13].T. Belytschko, Y.Y. Lu, L. Gu. Element-free Galerkin methods, Int. J. Numer. Meth. Eng. 1994; 37, 229-256.

[14].S. S. Ghorashi, S. Mohammadi, Saeed-Reza Sabbagh-Yazdi. Orthotropic enriched element free Galerkin method for fracture analysis of composites. Engineering Fracture Mechanics 2011; 78, 1906-1927.

[15].M. Fleming, Y. A. Chu, T. Belytschko. Enriched Element-Free Galerkin methods for crack tip fields, International Journal for Numerical Methods in Engineering 1997; 40, 1483-1504.

[16].G. Ventura et al. A vector level set method and new discontinuity approximations for crack growth by EFG, International Journal for Numerical Methods in Engineering 2002; 54, 923-944.

[17].P.H. Wen and M.H. Alibadi. Evaluation of mixed-mode stress intensity factors by the mesh-free Galerkin method: Static and dynamic. The Journal of Strain Analysis for Engineering Design 2009, 44, 273-286.

[18].Nguyen T.N., Bui T.Q., Zhang Ch., Truong T.T.. Crack growth modeling in elastic solids by the extended meshfree Galerkin 
radial point interpolation method. Engineering Analysis with Boundary Elements 2014; 44, 87-97.

[19].Lekhnitskii SG. Theory of an anisotropic elastic body. San Francisco: Holden-Day; 1963.

[20].Liu G. R. - Mesh Free Methods. Moving beyon the Finite Element Method. CRC Press LLC (2003).

[21].D. Motamedi, S. Mohammadi. Dynamic crack propagation analysis of orthotropic media by the extended finite element method. Int J Fract 2010; 161, 21-39.

[22].Aliabadi MH, Sollero P. Crack growth analysis in homogeneous orthotropic laminates. Comp Sci Technol 1998; 58, 1697-703.

[23]. Chu SJ, Hong CS. Application of the integral to mixed mode crack problems for anisotropic composite laminates. Engng Fract Mech 1990; 35(6), 1093-103.

[24]. Atluri SN, Kobayashi AS, Nakagaki MA. Finite element program for fracture mechanics analysis of composite material. Fract Mech Comp ASTM STP 1975; 593, 86-98.

[25].Kim JH, Paulino GH. Mixed-mode fracture of orthotropic functionally graded materials using finite elements and the modified crack closure method. Engnd Fract Mech 2002; 69, 1557-86. 